\title{
Surveillance of cirrhosis for hepatocellular carcinoma: a cost-utility analysis
}

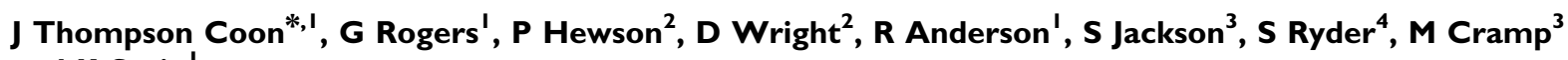 and K Stein'}

'Peninsula Technology Assessment Group (PenTAG), Peninsula College of Medicine and Denistry, (Universities of Plymouth and Exeter), Noy Scott House, Barrack Road, Exeter EX2 5DW, UK; ${ }^{2}$ School of Mathematics and Statistics, University of Plymouth, Drake Circus, Plymouth PL4 8AA, UK; ${ }^{3}$ Plymouth Hospitals NHS Trust, Derriford Hospital, Derriford Road, Plymouth PL6 8DH, UK; ${ }^{4}$ Wolfson Digestive Diseases Centre, Queen's Medical Centre,

Nottingham University Hospital NHS Trust, Derby Road, Nottingham NG7 2UH, UK

Using a decision-analytic model, we evaluated the effectiveness and cost-effectiveness of surveillance for hepatocellular carcinoma $(\mathrm{HCC})$ in individuals with cirrhosis. Separate cohorts with cirrhosis due to alcoholic liver disease, hepatitis B and hepatitis C were simulated. Results were also combined to approximate a mixed aetiology population. Comparisons were made between a variety of surveillance algorithms using $\alpha$-foetoprotein (AFP) assay and/or ultrasound at 6 - and 12-monthly intervals. Parameter estimates were obtained from comprehensive literature reviews. Uncertainty was explored using one-way and probabilistic sensitivity analyses. In the mixed aetiology cohort, 6-monthly AFP + ultrasound was predicted to be the most effective strategy. The model estimates that, compared with no surveillance, this strategy may triple the number of people with operable tumours at diagnosis and almost halve the number of people who die from HCC. The cheapest strategy employed triage with annual AFP (incremental cost-effectiveness ratio (ICER): $£ 20700$ per quality-adjusted life-year (QALY) gained). At a willingness-to-pay threshold of $£ 30000$ per QALY the most cost-effective strategy used triage with 6-monthly AFP (ICER: $£ 27600$ per QALY gained). The addition of ultrasound to this strategy increased the ICER to $£ 60100$ per QALY gained. Surveillance appears most cost-effective in individuals with hepatitis B-related cirrhosis, potentially due to younger age at diagnosis of cirrhosis. Our results suggest that, in a UK NHS context, surveillance of individuals with cirrhosis for HCC should be considered effective and cost-effective. The economic efficiency of different surveillance strategies is predicted to vary markedly according to cirrhosis aetiology.

British Journal of Cancer (2008) 98, I I66- | I75. doi: I0.1038/sj.bjc.660430 I www.bjcancer.com

Published online I April 2008

(C) 2008 Cancer Research UK

Keywords: cost-effectiveness; cost-utility; modelling studies; hepatocellular carcinoma; cirrhosis; surveillance

Hepatocellular carcinoma (HCC) occurs mainly in cases of cirrhosis, which, in turn, tend to be secondary to either alcoholic liver disease (ALD) or infection with hepatitis B or C viruses (HBVs/HCVs). Symptomatic HCC typically presents late with a bleak prognosis, whereas HCCs detected during formal surveillance are smaller, more likely to be uninodular and more commonly amenable to curative treatment (De Masi et al, 2005). For this reason, UK (Ryder, 2003), European (Bruix et al, 2001) and American (Bruix and Sherman, 2005) clinical guidelines recommend routine surveillance for HCC among individuals with cirrhosis, and approximately three-quarters of UK gastroenterologists undertake such a programme, mostly using a combination of periodic serum $\alpha$-foetoprotein (AFP) testing and ultrasound (US) (Lai et al, 2002).

However, consensus has not been reached as to the optimal surveillance strategy. We therefore developed a decision-analytic model to assess the effectiveness and cost-effectiveness of a range

*Correspondence: Dr J Thompson Coon;

E-mail: jo.thompson-coon@pms.ac.uk

Received 9 August 2007; revised 30 January 2008; accepted II February

2008; published online I April 2008 of different surveillance strategies in the United Kingdom. We considered populations with cirrhosis secondary to HBV or HCV infection, and as a result of ALD.

\section{MATERIALS AND METHODS}

\section{Overview of model}

We developed a state-transition (Markov) model using TreeAge Pro $^{\text {TM }} 2005$ (TreeAge Software, Williamstown, MA, USA) to compare alternative surveillance strategies. In this approach, disease progression is modelled as movement between different health states over time. Time is modelled as a series of fixed cycles, in this case 1 month, with probabilities of movement between states calculated per cycle. Costs and utility values are attached to each state, and the differences between the aggregated costs and health outcomes in each simulation are used to estimate the costeffectiveness of surveillance, expressed as incremental cost per quality-adjusted life-year (QALY) (Sonnenberg and Beck, 1993). Costs and QALYs were discounted at 3.5\% per year (HM Treasury, 2003). The perspective of the analysis is that of the UK NHS. 


\section{Simulated populations}

The population of interest is people with compensated cirrhosis aged 70 years or less with no pre-existing medical conditions that might preclude treatment with liver transplantation (OLT) or hepatic resection (including current alcohol or intravenous drug use). The model considers three cirrhosis aetiologies (ALD, HBV and $\mathrm{HCV}$ ). Results were also combined to simulate a mixed aetiology cohort, consisting of the following proportions (based on an average of estimates provided by gastroenterologists in several centres around the United Kingdom): $57.6 \%$ ALD, $7.3 \%$ HBV and $35.1 \% \mathrm{HCV}$.

\section{Model structure}

The structure of the model is shown in Figure 1. For the natural history component of the model, we defined three classes of HCC: small $(<2 \mathrm{~cm}$ in diameter), medium $(2-5 \mathrm{~cm})$ and large $(>5 \mathrm{~cm})$. Tumour characteristics in terms of detectability and treatability are reflected in the transition probabilities. The following simplifying assumptions were made: (i) progression from cirrhosis to decompensated cirrhosis is irreversible; (ii) the rate of incidence of HCC is the same in compensated and decompensated livers; (iii) tumour diameter is used as a surrogate index of all characteristics of tumour progression (multifocal tumours are not modelled separately, since tumour nodularity is heterogeneous in the populations from which parameters have been drawn; therefore, what our model defines as 'medium' tumours would, in real-world practice, include those with multiple, small nodules that would not preclude transplantation, and a 'large' tumour may be thought to include those which are diffuse in nature); (iv) the presence of an HCC is only associated with additional mortality risk when it becomes 'large' (at which point it is also very likely to become symptomatic) and (v) compensated cirrhosis is not subject to an excess mortality rate, as the primary causes of death in these individuals are those already accounted for in the model (i.e., progression to decompensation and/or HCC).

The surveillance programme is superimposed onto the disease process. We simulated six different surveillance regimes, consisting of AFP-led, US-led and combined screening at 6- or 12monthly intervals (Figure 2). These were based on European guidelines, which recommend that the diagnosis of HCC be based on two coincident imaging techniques (Bruix et al, 2001). For comparison, we also modelled an arm simulating no surveillance. The possibility of incidental/symptomatic presentation of HCC is modelled at all stages of disease. All confirmatory imaging is by CT scan. We assumed $100 \%$ compliance with the surveillance programme in the base-case analysis.

We modelled a mixed treatment approach using OLT and resection. People can enter the OLT waiting list following diagnosis of either a surgically treatable HCC or decompensated cirrhosis. Each person is as likely to receive a liver as any other, regardless of the reason for listing. While on the waiting list, people are subject to the same natural history process as those prelisting, and no 'bridging' therapies are simulated. People who undergo successful surgical treatment enter a simplified disease process in which excess mortality rates and associated costs and utilities encompass the spectrum of possible post-treatment experiences. There is no waiting list for liver resection. Some people are deemed unsuitable for either surgical treatment. A proportion of people with surgically untreatable small and medium-sized tumours receive palliative treatment with radiofrequency ablation and percutaneous ethanol injection. On progression to 'terminal HCC large', an excess mortality with associated costs and utilities is applied that reflects the palliation provided by transarterial chemoembolisation for a proportion of people.

\section{Parameters}

Model parameters are listed in Tables 1-3. Estimates were obtained from literature searches in a range of electronic databases

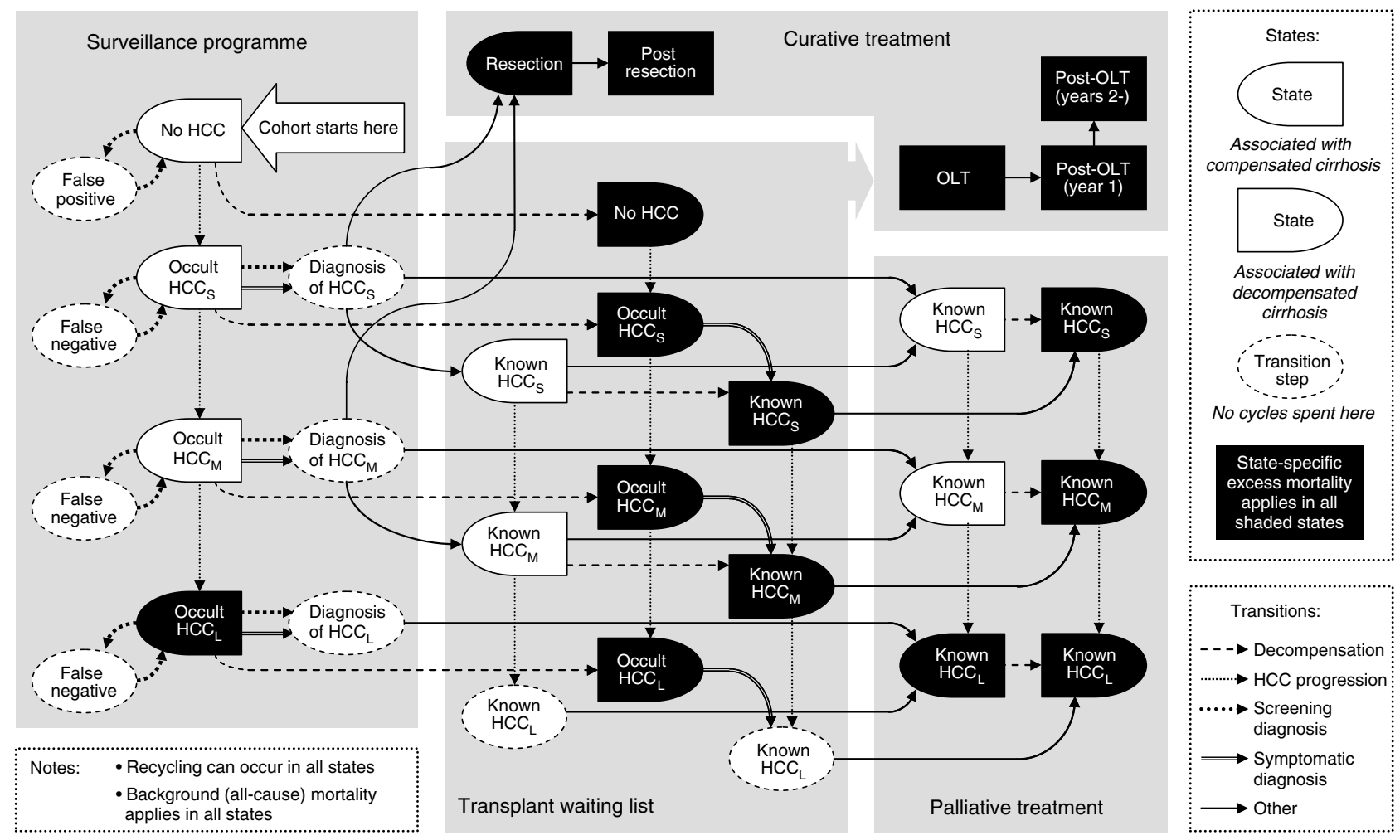

Figure I Influence diagram illustrating the natural history and treatment pathways simulated in the model. 

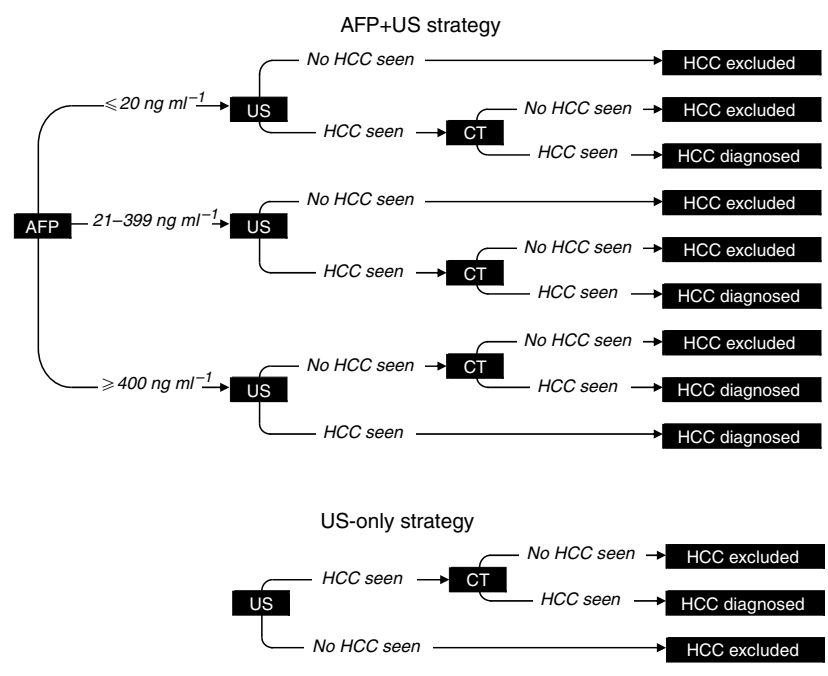

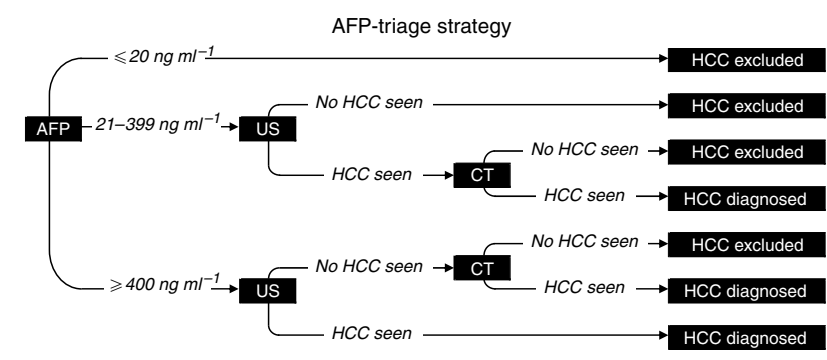

Notes

- Each screening strategy was applied at both 6-and 12-monthly intervals

- True-negative diagnoses (i.e. HCC excluded in no HCC state) and falsenegative diagnoses (i.e. HCC excluded in occult HCC states) return to surveillance programme

- False-positive diagnoses (i.e. HCC diagnosed in no HCC state) incur additional costs (to simulate expense entailed in discovering mistaken diagnosis in the workup for treatment) and return to surveillance programme

- True-positive diagnoses (i.e. HCC diagnosed in occult HCC states) proceed to treatment programme or palliative care

Figure 2 Decision trees illustrating the three screening algorithms investigated in the model.

Table I Model parameters: transition probabilities defining natural history, surveillance and therapy

\begin{tabular}{|c|c|c|c|c|c|}
\hline \multirow[b]{2}{*}{ Parameter } & \multirow[b]{2}{*}{ Cohort } & \multirow[b]{2}{*}{ Value } & \multirow[b]{2}{*}{ Source } & \multicolumn{2}{|c|}{ Range } \\
\hline & & & & Lower & Upper \\
\hline Starting age of cohort (mean years at diagnosis) & $\begin{array}{l}\text { ALD } \\
\text { HBV } \\
\text { HCV }\end{array}$ & $\begin{array}{l}53.3 \\
44.0 \\
54.0\end{array}$ & $\begin{array}{l}\text { Roberts et al (2005) } \\
\text { Fattovich et al (1995) } \\
\text { Fattovich et al (1997) }\end{array}$ & $\begin{array}{l}43.3 \\
34.0 \\
44.0\end{array}$ & $\begin{array}{l}63.3 \\
54.0 \\
64.0\end{array}$ \\
\hline Gender of cohort (\% male) & $\begin{array}{l}\text { ALD } \\
\text { HBV } \\
\text { HCV }\end{array}$ & $\begin{array}{l}70.1 \\
86.5 \\
58.1\end{array}$ & $\begin{array}{l}\text { ONS mortality statistics } \\
\text { Fattovich et al (1995) } \\
\text { Fattovich et al (1997) }\end{array}$ & $\begin{array}{l}50.0 \\
82.6 \\
53.1\end{array}$ & $\begin{array}{l}90.2 \\
89.7 \\
62.9\end{array}$ \\
\hline Upper age limit for surveillance & & 70 & Authors' assumption & 60 & 80 \\
\hline Incidence of decompensation (\% per year) & $\begin{array}{l}\text { ALD } \\
\text { HBV } \\
\text { HCV }\end{array}$ & $\begin{array}{l}3.3 \\
3.3 \\
5.3\end{array}$ & $\begin{array}{l}\text { Assumed as for HBV } \\
\text { Fattovich et al (2002) } \\
\text { Fattovich et al (2002) }\end{array}$ & $\begin{array}{l}1.8 \\
1.8 \\
3.9\end{array}$ & $\begin{array}{l}7.0 \\
6.0 \\
7.0\end{array}$ \\
\hline Incidence of HCC (\% per year) & $\begin{array}{l}\text { ALD } \\
\text { HBV } \\
\text { HCV }\end{array}$ & $\left.\begin{array}{l}1.7 \\
2.2 \\
3.7\end{array}\right\}$ & Fattovich et al (2004) & $\begin{array}{l}1.2 \\
1.6 \\
3.2\end{array}$ & $\begin{array}{l}2.2 \\
2.8 \\
4.2\end{array}$ \\
\hline $\begin{array}{l}\text { Tumour growth rate (volume doubling time) (days) } \\
\text { Proportion diagnosed with } \mathrm{HCC}_{S} \text { assigned to resection/OLT/palliative care } \\
\text { Proportion diagnosed with } \mathrm{HCC}_{M} \text { assigned to resection/OLT/palliative care } \\
\text { Median days on } O L T \text { waiting list } \\
\text { Excess mortality due to compensated cirrhosis (\% per annum) }\end{array}$ & & $\begin{array}{l}127^{\mathrm{a}} \\
20: 75: 5 \\
5: 85: 10 \\
72^{\mathrm{e}} \\
0\end{array}$ & $\begin{array}{l}\text { Taouli et al (2005) } \\
\text { Authors' assumption } \\
\text { Authors' assumption } \\
\text { UK Transplant } \\
\text { Authors' assumption }\end{array}$ & $\begin{array}{l}80^{\mathrm{b}} \\
10: 85: 5 \\
2: 88: 10 \\
68^{f} \\
0\end{array}$ & $\begin{array}{l}203^{c} \\
30: 65: 5 \\
10: 80: 10 \\
76^{g} \\
5\end{array}$ \\
\hline Excess mortality due to decompensated cirrhosis (\% per annum) & $\begin{array}{l}\text { ALD } \\
\text { HBV } \\
\text { HCV }\end{array}$ & $\begin{array}{l}17.7 \\
22.5 \\
12.9\end{array}$ & $\begin{array}{l}\text { h } \\
\text { Fattovich et al (2002) } \\
\text { Fattovich et al (1997) }\end{array}$ & $\begin{array}{l}12.7 \\
18.9 \\
12.7\end{array}$ & $\begin{array}{l}32.5 \\
32.5 \\
14.0\end{array}$ \\
\hline Survival rate following OLT (\% at 90 days/I year/5 years) & $\begin{array}{l}\text { ALD } \\
\text { HBV } \\
\text { HCV }\end{array}$ & $\left.\begin{array}{l}94: 92: 55 \\
85: 78: 69 \\
93: 88: 86\end{array}\right\}$ & UK Transplant & $\begin{array}{l}87: 85: 38 \\
97: 66: 54 \\
88: 82: 41\end{array}$ & $\begin{array}{l}\text { |00:100:7| } \\
95: 90: 83 \\
97: 93: 7 \mid\end{array}$ \\
\hline $\begin{array}{l}\text { Survival rate following resection (\% at } 90 \text { days } / / \text { year } / 3 \text { years } / 5 \text { years) } \\
\text { Excess mortality associated with occult } H C C_{L} \text { (\% per year) } \\
\text { Excess mortality associated with known } H C C_{L} \text { (\% per year) } \\
\text { Background (all-cause) mortality }\end{array}$ & & $\begin{array}{l}96: 85: 62: 51 \\
72.9 \\
64.4\end{array}$ & $\begin{array}{l}\text { Llovet et al (1999) } \\
\text { Greten et al (2005) } \\
\text { Government Actuary's } \\
\text { Department (2006) }\end{array}$ & $\begin{array}{l}89: 79: 54: 36 \\
\quad 34.6 \\
33.6 \\
-\end{array}$ & $\begin{array}{l}99: 88: 76: 58 \\
97.3 \\
84.8 \\
-\end{array}$ \\
\hline $\begin{array}{l}\text { Probability of AFP }<20 \mathrm{ng} \mathrm{ml}^{-1} / 20-400 \mathrm{ng} \mathrm{m}^{-1} />400 \mathrm{ng} \mathrm{ml}^{-1} \\
\text { In } \mathrm{HCC}_{S} \\
\text { In } \mathrm{HCC}_{\mathrm{M}} \\
\text { In HCC } \mathrm{HC} \\
\text { With no HCC }\end{array}$ & & $\begin{array}{l}\left.\begin{array}{l}0.352: 0.568: 0.080 \\
0.378: 0.500: 0.122 \\
0.222: 0.444: 0.334\end{array}\right\} \\
0.906: 0.088: 0.006\end{array}$ & $\begin{array}{l}\text { Pooled IPDk } \\
\text { Trevisani et al (200I) }\end{array}$ & $\begin{array}{l}0.261: 0.464: 0.03 \\
0.276: 0.389: 0.06 \\
0.063: 0.189: 0.12 \\
0.853: 0.054: 0.00\end{array}$ & $\begin{array}{l}0.456: 0.667: 0.155 \\
0.492: 0.611: 0.215 \\
0.547: 0.733: 0.646 \\
0.941: 0.140: 0.033\end{array}$ \\
\hline
\end{tabular}




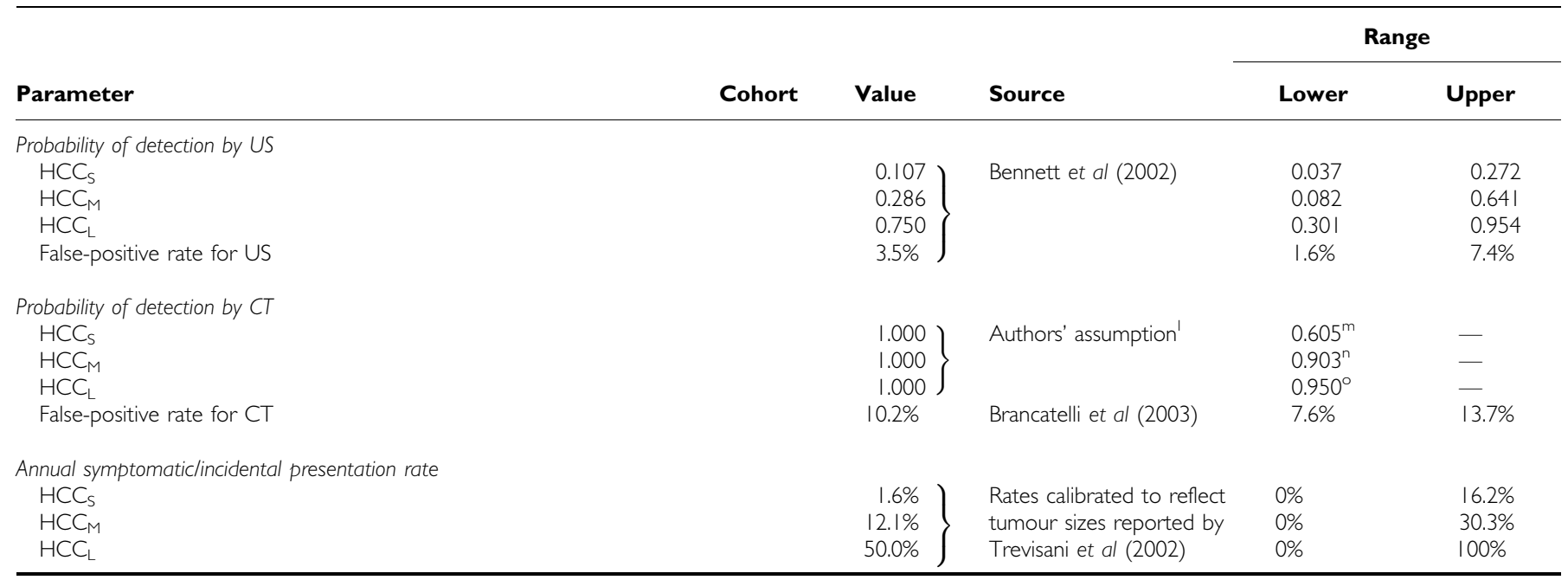

$\mathrm{AFP}=\alpha$-foetoprotein; $\mathrm{ALD}=$ alcoholic liver disease; $\mathrm{CT}=$ computed tomography; $\mathrm{HBV}$; hepatitis $\mathrm{B}$ virus; $\mathrm{HCC}=$ hepatocellular carcinoma; $\mathrm{HCC}=$ large hepatocellular carcinoma; $\mathrm{HCC}_{M}=$ medium hepatocellular carcinoma; $\mathrm{HCC}_{S}=$ small hepatocellular carcinoma; $\mathrm{HCV}=$ hepatitis $\mathrm{C}$ virus; IPD = individual patient data; $\mathrm{OLT}=$ orthotopic liver transplantation; ONS = Office of National Statistics; US =ultrasound. ${ }^{a}$ Equivalent to a monthly probability of progression from $\mathrm{HCC}_{S}$ to $\mathrm{HCC}_{M}=0.056$; $\mathrm{HCC}_{M}$ to $H C C_{L}=0.036$. ${ }^{b}$ Equivalent to a monthly probability of progression from $\mathrm{HCC}_{S}$ to $\mathrm{HCC}_{M}=0.036 ; \mathrm{HCC}_{M}$ to $H C C_{L}=0.023$. 'Equivalent to a monthly probability of progression from $\mathrm{HCC}_{S}$ to $\mathrm{HCC}_{M}=0.089 ; \mathrm{HCC}_{M}$ to $\mathrm{HCC}_{\mathrm{L}}=0.056$. ${ }^{\mathrm{d}}$ All individuals have the same probability of receiving a transplant, regardless of reason for listing. ${ }^{\mathrm{E}}$ Equivalent to a monthly probability of receiving a transplant $=0.254$. ${ }^{\mathrm{f}}$ Equivalent to a monthly probability of receiving a transplant $=0.242 .{ }^{g}$ Equivalent to a monthly probability of receiving a transplant $=0.267 .{ }^{h}$ Average of HBV and HCV values in the absence of a reliable ALD-specific estimate. 'Assuming 33\% of patients receive TACE. 'Variable age- and sex-specific rates, increasing as the cohort ages. ${ }^{\text {K}}$ Pooled from individual patient data reported in six separate series (Sheu et al, 1985; Ebara et al, 1986; Cottone et al, 1988; Oka et al, 1990; Cottone et al, 1994; Zoli et al, 1996). 'Because, in the algorithm simulated by the model, the use of CT is limited to a second line, confirmatory context, our base-case assumption was that all such scans would accurately identify HCC, where present. Although CT is subject to a significant false-negative rate when used in blinded, first-line assessments (Taouli et al, 2004; Baron and Brancatelli, 2004), we made the assumption that such fallibility should not be apparent in this context. The impact of this assumption was tested in sensitivity analyses. 'MSource: Valls et al (2004). "'Source: Spreafico et al (1997). ${ }^{\circ}$ Authors' assumption, in the absence of suitable published data source. On the basis of the rationale that sensitivity should be greater than the evidence-based figure adopted for $\mathrm{HCC}_{M}$, but less than $100 \%$.

(full details and strategies available from the authors). We sought data that fulfilled the following criteria: large, recent studies of UK patients with a diagnosis of cirrhosis (with details of aetiology). For parameters in which there were no UK-based studies available, we sought data from countries with a similar disease profile. Cost data were obtained from national (UK NHS; Department of Health (DoH), 2005) sources where available, supplemented by data from a recent UK-based observational study of patients with HCV (Wright et al, 2006). Historical values were inflated to 2004 prices.

\section{Analysis of uncertainty}

Extensive one-way sensitivity analyses were undertaken to explore, which of the input parameters had the greatest impact on results. For simplicity, these were performed using a single-core comparison: 6-monthly AFP + US vs no surveillance. Owing to the paucity of reliable estimates for US sensitivity and the possibility that these estimates do not accurately reflect current practice, we examined the impact of simultaneously varying the sensitivity of US for detecting tumours over a range of correlated values from 5 to 50,10 to 75 and 50 to $100 \%$ for small, medium and large tumours, respectively. We also performed scenario analyses testing less optimistic assumptions about patient compliance.

Probabilistic sensitivity analysis was also undertaken. Ten thousand Monte Carlo simulations per aetiology were run, with key input values randomly drawn from probabilistic density functions in each iteration. Distributions can be obtained from the authors.

\section{RESULTS}

\section{Effectiveness of surveillance}

Table 4 summarises the effectiveness of each surveillance strategy in the mixed aetiology cohort. The 6-monthly AFP + US was most effective across all outcomes, more than tripling the number of HCCs diagnosed while operable, and almost halving the number dying from HCC, when compared with no surveillance. However, the cheapest strategy, annual AFP-triage, still achieved substantial gains: for example, more than doubling the number of operable HCC found and increasing the number of small tumours found more than six-fold.

\section{Cost - utility of surveillance}

Cost-utility results are shown in Table 5. In an incremental analysis, neither of the US-only strategies would be considered (since they are both slightly less effective and more costly than surveillance at the same frequency with AFP-triage). Therefore, in the mixed aetiology cohort the cheapest surveillance strategy is annual AFP-triage, with incremental cost-utility of $£ 20700$ per QALY. Doubling the frequency of surveillance would increase the mean number of QALYs by 0.035 at a cost of $£ 1000$ each, giving an incremental cost-effectiveness ratio (ICER) of $£ 27000$ per QALY gained.

\section{Deterministic sensitivity analyses}

The cost-utility estimates appear to be most sensitive to changes in tumour growth rate, mortality following OLT and excess 
Table 2 Model parameters: costs

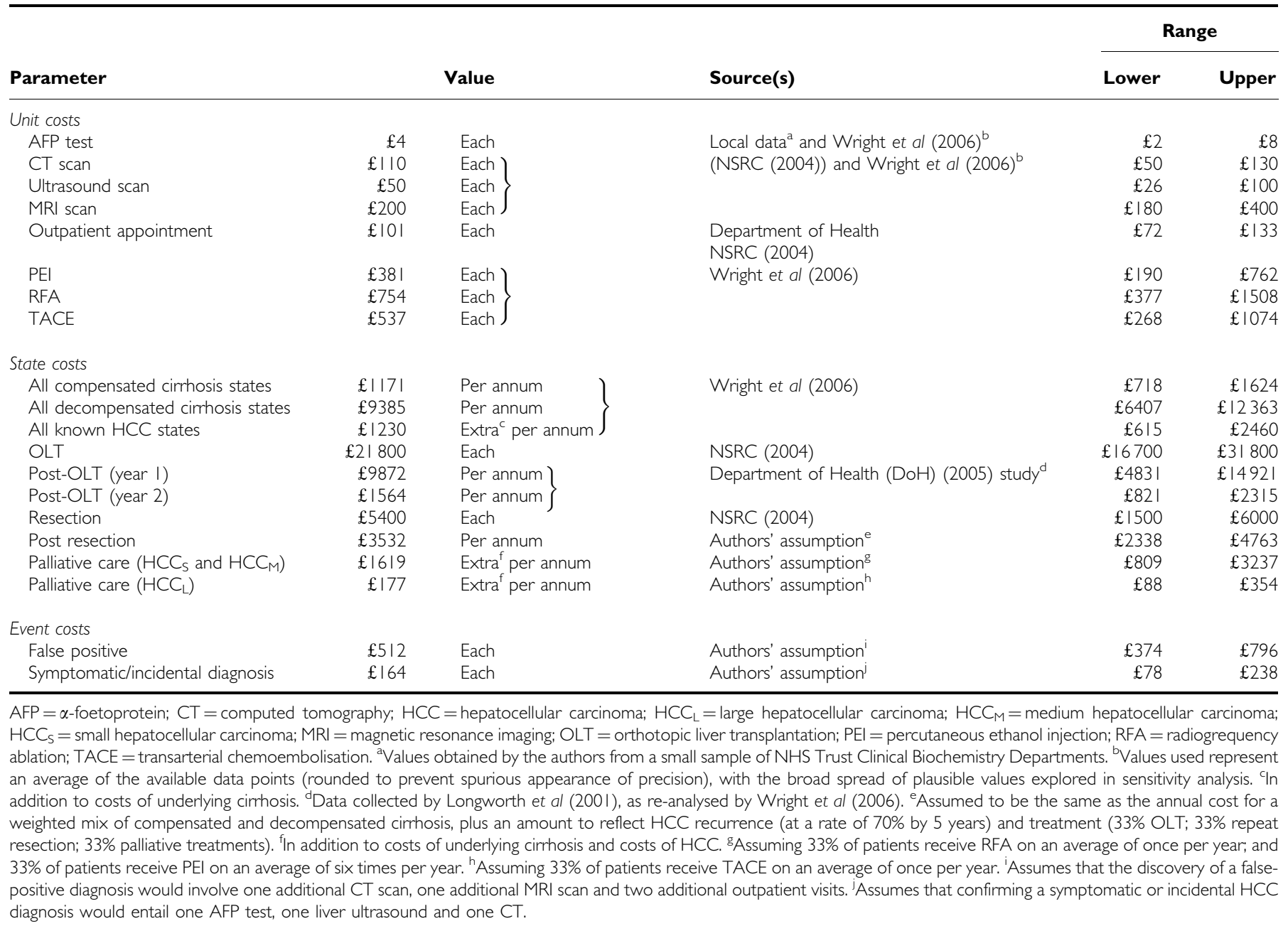

Table 3 Model parameters: utility values

\begin{tabular}{|c|c|c|c|c|c|}
\hline \multirow[b]{2}{*}{ Health state } & \multirow[b]{2}{*}{ Markov states in which applied } & \multirow[b]{2}{*}{ Value } & \multirow[b]{2}{*}{ Source } & \multicolumn{2}{|c|}{ Range } \\
\hline & & & & Lower & Upper \\
\hline Decompensated cirrhosis & $\begin{array}{l}\text { All decompensated cirrhosis states ( } \pm \text { known or occult } \mathrm{HCC}_{S} \text { or } \mathrm{HCC}_{\mathrm{M}} \text {, } \\
\text { including patients on the OLT waiting list) }\end{array}$ & 0.66 & Chong et al (2003) & 0.46 & 0.86 \\
\hline $\mathrm{HCC}$ & Terminal $\mathrm{HCC}_{\mathrm{L}}$ & 0.64 & Chong et al (2003) & 0.44 & 0.86 \\
\hline Post-OLT (year 2+) & Post-OLT (year 2 onwards) & 0.73 & Ratcliffe et al (2002) & 0.67 & 0.78 \\
\hline Resection & Resection (month of) & 0.50 & Authors' assumption & 0.30 & 0.60 \\
\hline Post resection & Post resection & 0.73 & & 0.62 & 0.84 \\
\hline
\end{tabular}

$\mathrm{HCC}=$ hepatocellular carcinoma; $\mathrm{HCC}_{\mathrm{L}}=$ large hepatocellular carcinoma; $\mathrm{HCC}_{M}=$ medium hepatocellular carcinoma; $\mathrm{HCC}_{\mathrm{S}}=$ small hepatocellular carcinoma; $\mathrm{OLT}=$ orthotopic liver transplantation. ${ }^{a}$ Weighted average of the values adopted for compensated and decompensated cirrhosis.

mortality associated with undiagnosed large tumours. Quality of life in compensated cirrhosis and following OLT are also important, as are costs associated with US and OLT. When the cirrhosis aetiologies are considered separately, the mean age at diagnosis in individuals with HBV-related cirrhosis becomes an important variable.

Increases in US sensitivity lead to improved effectiveness in all surveillance strategies. At both annual and 6-monthly frequencies, US-led surveillance becomes more effective than AFP-triage surveil- lance when it can be assumed that US is at least sensitive enough to detect one in five small tumours, one in three medium tumours and two in three large tumours. However, when costs are also considered, it is only in the HBV cohort that US becomes more cost-effective than AFP-triage surveillance at the same frequencies.

When we examined imperfect patient compliance with surveillance, we found a noticeable reduction in effectiveness. However, there was a commensurate reduction in costs, so incremental costeffectiveness results were not greatly altered. 
Lifetime effectiveness of surveillance

\begin{tabular}{|c|c|c|c|c|c|c|c|}
\hline & $\begin{array}{c}\text { No } \\
\text { surveillance }\end{array}$ & $\begin{array}{c}\text { Annual } \\
\text { AFP-triage }\end{array}$ & $\begin{array}{c}\text { Annual } \\
\text { US }\end{array}$ & $\begin{array}{c}\text { Annual } \\
\text { AFP+US }\end{array}$ & $\begin{array}{l}\text { 6-monthly } \\
\text { AFP-triage }\end{array}$ & $\begin{array}{c}\text { 6-monthly } \\
\text { US }\end{array}$ & $\begin{array}{c}\text { 6-monthly } \\
\text { AFP+US }\end{array}$ \\
\hline$\%$ with operable HCC & $5.1 \%$ & $11.9 \%$ & $11.7 \%$ & $13.5 \%$ & $15.3 \%$ & $15.0 \%$ & $16.9 \%$ \\
\hline$\% \mathrm{HCC}_{\mathrm{S}}$ at diagnosis & $0.3 \%$ & $1.9 \%$ & $1.5 \%$ & $2.3 \%$ & $3.1 \%$ & $2.6 \%$ & $3.7 \%$ \\
\hline$\% \mathrm{HCC}_{M}$ at diagnosis & $2.1 \%$ & $3.8 \%$ & $4.1 \%$ & $4.2 \%$ & $4.2 \%$ & $4.6 \%$ & $4.4 \%$ \\
\hline$\%$ getting OLTs & $17.1 \%$ & $19.1 \%$ & $19.1 \%$ & $19.2 \%$ & $20.1 \%$ & $20.0 \%$ & $20.3 \%$ \\
\hline$\%$ OLTs for known HCC & $8.3 \%$ & $20.3 \%$ & $20.0 \%$ & $23.2 \%$ & $25.3 \%$ & $24.9 \%$ & $27.9 \%$ \\
\hline$\%$ dying of HCC & $19.9 \%$ & $14.7 \%$ & $14.9 \%$ & $13.5 \%$ & $12.0 \%$ & $12.3 \%$ & $10.8 \%$ \\
\hline NNS to prevent I death ${ }^{\mathrm{a}}$ & - & 19 & 20 & 15 & 13 & 13 & II \\
\hline$\%$ dead by age 75 years & $69.3 \%$ & $68.4 \%$ & $68.5 \%$ & $68.2 \%$ & $68.0 \%$ & $68.0 \%$ & $67.8 \%$ \\
\hline NNS to prevent I death ${ }^{b}$ & - & 114 & 117 & 93 & 78 & 79 & 68 \\
\hline
\end{tabular}

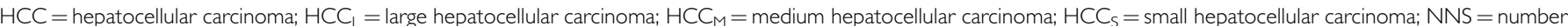

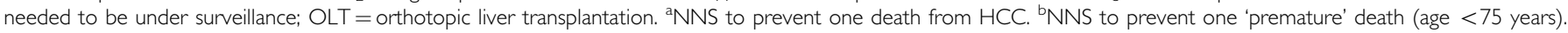

Table 5 Cost-utility analyses

\begin{tabular}{|c|c|c|c|c|c|}
\hline Strategy & Cost $(f)$ & Utility (QALYs) & \multicolumn{3}{|c|}{ Incremental analysis } \\
\hline No surveillance & $£ 26100$ & 9.359 & & & \\
\hline Annual AFP-triage & $£ 27400$ & 9.410 & $£ 1300$ & 0.051 & $£ 24800$ \\
\hline Annual US & $£ 27700$ & 9.410 & & Extendedly dominated & \\
\hline Annual AFP+US & $£ 28100$ & 9.422 & & Extendedly dominated & \\
\hline 6-monthly AFP+US & $£ 29200$ & 9.445 & $£ 1000$ & 0.011 & $£ 88000$ \\
\hline \multicolumn{6}{|l|}{$H B V$} \\
\hline No surveillance & $£ 29600$ & 10.858 & & & \\
\hline Annual AFP-triage & $£ 31700$ & 11.069 & $£ 2100$ & 0.211 & $£ 10200$ \\
\hline Annual US & $£ 32100$ & 11.066 & & Dominated & \\
\hline Annual AFP+US & $£ 32700$ & 11.119 & & Extendedly dominated & \\
\hline \multicolumn{6}{|l|}{$\mathrm{HCV}$} \\
\hline No surveillance & $£ 27600$ & 8.087 & & & \\
\hline Annual AFP-triage & $£ 29500$ & 8.172 & $£ 1900$ & 0.085 & $£ 22200$ \\
\hline Annual US & $£ 29700$ & 8.172 & & Extendedly dominated & \\
\hline Annual AFP+US & $£ 30300$ & 8.193 & & Extendedly dominated & \\
\hline 6-monthly AFP-triage & $£ 30600$ & 8.212 & $£ 1100$ & 0.040 & $£ 27600$ \\
\hline 6-monthly US & $£ 31000$ & 8.213 & & Extendedly dominated & \\
\hline 6-monthly AFP+US & $£ 31600$ & 8.232 & $£ 1000$ & 0.020 & $£ 50400$ \\
\hline \multicolumn{6}{|l|}{ Mixed aetiology } \\
\hline No surveillance & $£ 26900$ & 9.021 & & & \\
\hline Annual AFP-triage & $£ 28400$ & 9.096 & $£ 1500$ & 0.075 & $£ 20700$ \\
\hline Annual US & $£ 28800$ & 9.096 & & Dominated & \\
\hline Annual AFP+US & $£ 29200$ & 9.114 & & Extendedly dominated & \\
\hline
\end{tabular}

$\mathrm{AFP}=\alpha$-foetoprotein; $\mathrm{ALD}=$ alcoholic liver disease; $\mathrm{HBV}$; hepatitis B virus; $\mathrm{HCV}=$ hepatitis $\mathrm{B}$ virus; ICER = incremental cost-effectiveness ratio; $\mathrm{QALY}=$ quality-adjusted lifeyear; US = ultrasound. Discount rate of $3.5 \%$ per annum applied to all costs and benefits.

The model is extremely sensitive to the discount rate applied (3.5\% per year for both costs and utilities in the base case). The ICER for 6-monthly AFP + US compared with no surveillance ranges from $£ 19400$ per QALY if no discounting is applied to $£ 35800$ per QALY if rates of $6 \%$ are used for both costs and utilities.

\section{Probabilistic sensitivity analysis}

Figure 3 shows cost-effectiveness acceptability curves (Fenwick et al, 2001; Fenwick et al, 2004) for ALD, HBV, HCV and the mixed cohort. These graphs show the probability that each strategy would be considered the most cost-effective (in terms of highest net 

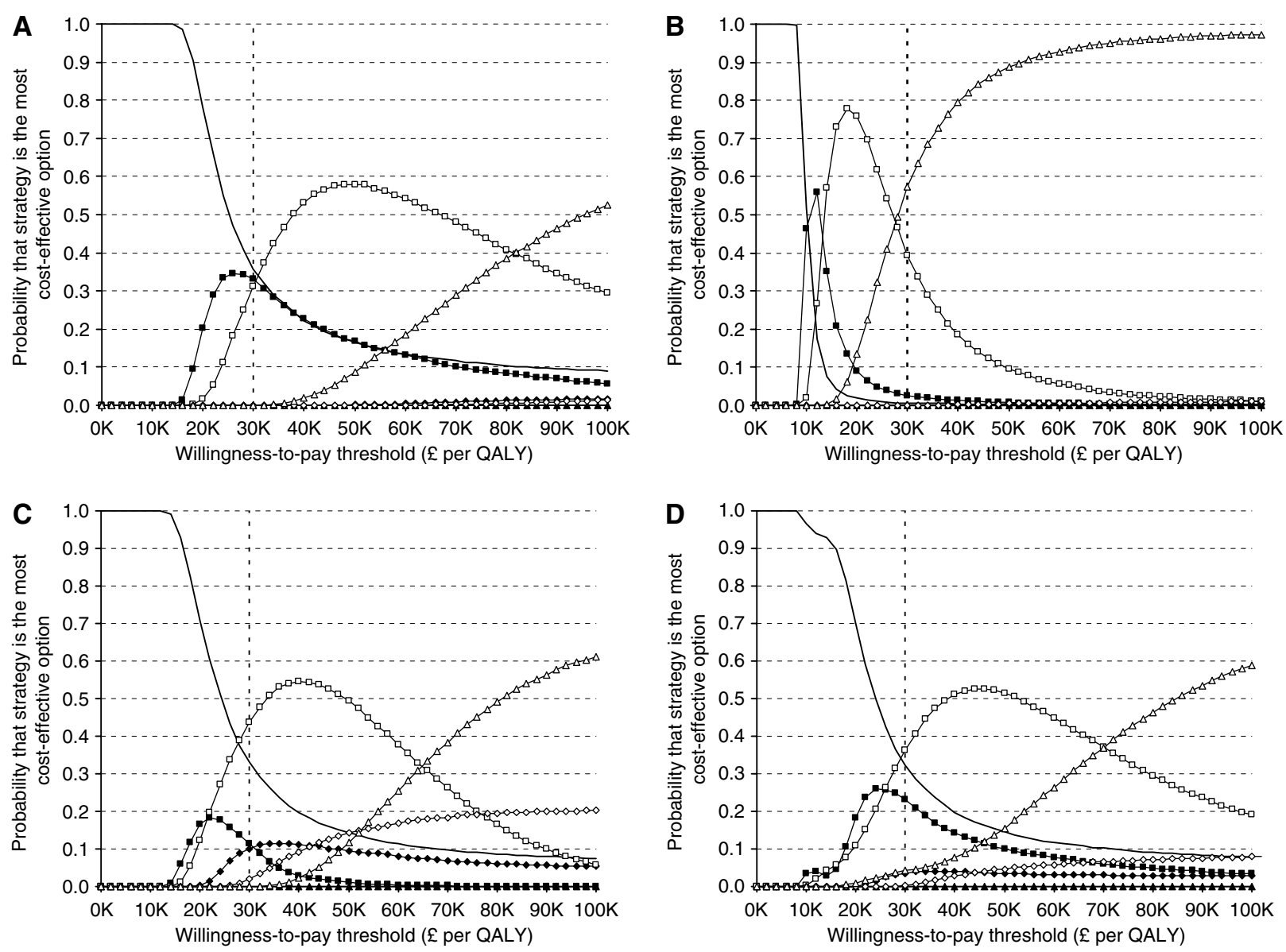

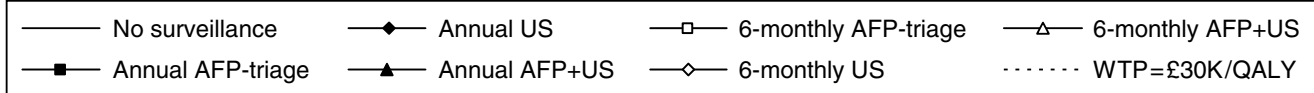

Figure 3 Cost-effectiveness acceptability curves, showing relative probability of maximal cost-effectiveness among surveillance strategies. (A) ALD-related cirrhosis; (B) HBV-related cirrhosis; (C) HCV-related cirrhosis; (D) mixed aetiology cohort (weighting: 57.6\% ALD; 7.3\% HBV; 35. I\% HCV). Maximal costeffectiveness reflects the proportion of Monte Carlo simulations (10000 per aetiology) in which each strategy generated the highest net monetary benefit.

monetary benefit) at different levels of willingness to pay for a QALY.

At a willingness-to-pay threshold of $£ 30000$ per QALY, the most intensive surveillance protocol simulated (6-monthly AFP + US) is only likely to be considered cost-effective in individuals with HBVrelated cirrhosis. In those with HCV-related cirrhosis, 6-monthly AFP-triage is more likely to be considered cost-effective; indeed, willingness to pay would have to rise to around $£ 65000$ per QALY before 6-monthly AFP + US becomes most likely to be considered cost-effective in this population. In individuals with ALD-related cirrhosis, there is uncertainty about which strategy would be most cost-effective at a willingness-to-pay threshold of $£ 30000$ per QALY, with no surveillance, annual AFP-triage and 6-monthly AFP-triage having approximately equal likelihood of maximal cost-effectiveness.

In the mixed aetiology cohort, which approximates the decision framework if a single strategy is to be adopted across all aetiologies, surveillance of any kind can only be recommended if willingness to pay approaches $£ 30000$ per QALY. At this level, 6monthly AFP-triage appears to be the most cost-effective surveillance protocol, and remains the foremost option until willingness to pay reaches very high levels. This analysis suggests that society would have to be prepared to spend nearly $£ 70000$ per QALY gained before the most effective strategy - 6-monthly
AFP + US - could confidently be assumed to provide best value for money.

\section{DISCUSSION}

\section{Summary of main findings}

Our analysis suggests that, in patients with cirrhosis, surveillance strategies for HCC are effective, and can often be considered costeffective. The most effective strategy for a mixed aetiology cohort of individuals with cirrhosis is AFP assay combined with US imaging on a 6-monthly basis. However, when costs are taken into account, using AFP as a triage step may be preferable. Surveillance is much more likely to be cost-effective in those with HBV-related cirrhosis, while surveillance of people with ALD-related cirrhosis appears least economically efficient.

\section{Interpretation of findings}

According to our simulation, the economic efficiency of different surveillance strategies can be expected to vary substantially according to cirrhosis aetiology. As a result, the most efficient mode of resource allocation, from a purely decision-analytic 
viewpoint, would be to offer surveillance of differing intensity to each subgroup. However, apart from the practical complications of establishing different recall pathways for different patient groups, concerns might also be raised about the ethical implications of this approach. For instance, one-way sensitivity analysis suggested that the particularly good value offered in the HBV group may be substantially due to the younger age of the cohort. By implication, then, there may be further subgroups of individuals with HCV and ALD, diagnosed with cirrhosis at a younger age, in which more intensive surveillance might be particularly cost-effective.

Our results also suggest that reports of the AFP test's demise (Sherman, 2001) may be exaggerated, particularly if one adopts a cost-effectiveness perspective. We believe one reason for this is that previous authors may have failed to account fully for tumour size in their analyses. Although the AFP test has been found to be relatively insensitive for detecting HCC in general (Trevisani et al, 2001), it has the substantial advantage that its sensitivity is only weakly correlated with tumour size, meaning that it should be a valuable aid to the detection of some of the smallest, most easily treated tumours. According to the evidence used in our model, $65 \%$ of tumours less than $2 \mathrm{~cm}$ in diameter secrete $20 \mathrm{ng} \mathrm{ml}^{-1}$ or more of AFP (although this figure may be an overestimate, with the true proportion around 46\%; Farinati et al, 2006). In contrast, our model is configured to simulate US sensitivity of only $10.7 \%$ for the smallest category of tumour (Bennett et al, 2002). Although this is at the pessimistic end of the range of available evidence, it should not be seen as an outlying estimate. Every study that has used an optimal reference standard (explant pathology) to investigate the diagnostic capabilities of US, in this setting, has reported disappointing sensitivity for the tumours $\leqslant 2 \mathrm{~cm}$ in diameter: 13.8\% (Kim et al, 2001), 22.2\% (Rode et al, 2001) and $30.0 \%$ (Liu et al, 2003). Even if one was to adopt the most positive estimate available, all robust evidence suggests that US is less sensitive than AFP assay for the detection of the smallest tumours.

Additionally, AFP is a very cheap test and, inevitably, this is a crucial consideration from a cost-effectiveness perspective. The fact that current guidelines do not recommend using AFP screening may reflect the poor quality of current evidence or a lack of explicit attention to cost-effectiveness considerations during the development of clinical guidelines. However, a strategy led by one single diagnostic modality will always run the risk of serial false-negative findings, and this setting provides a good example (some tumours never secrete AFP and will therefore never be detected using an AFP-led approach and, equally, some tumours will infiltrate diffusely and resist US detection).

Because tumour growth rate had a clear influence on costeffectiveness in the one-way sensitivity analysis, we investigated this factor further. We performed stratified scenario analyses, simulating three mixtures of slow-growing and fast-growing tumours, instead of applying one average growth rate throughout the model. While the combination of growth rates had an impact on the effectiveness and cost-effectiveness of surveillance (the more fast-growing HCCs, the more cost-effective surveillance becomes), the incremental relationship between surveillance strategies was preserved. The only practical implication of these additional findings is to suggest that, if the true mix of HCCs features a preponderance of slow-growing tumours, it may not be cost-effective to offer any surveillance strategy at 6-monthly intervals.

\section{Strengths of the evaluation}

This is the first analysis of the effectiveness and cost-effectiveness of surveillance of cirrhosis for HCC in the UK NHS. Comprehensive literature searches were conducted to inform the model parameters, wherever possible choosing data either derived from the UK population or most likely to be applicable to the UK population.
Extensive exploration of model structures and uncertainty suggest that our model more appropriately captures the disease and surveillance process and impacts than previous studies in this field. While we have assumed that decompensated cirrhosis is irreversible, we showed in one-way sensitivity analysis that our results are not greatly influenced by alterations in the annual rate of progression from compensated to decompensated cirrhosis. From this, it is safe to infer that allowing some regression from decompensated back to compensated cirrhosis would not significantly alter our main results. By accounting for the substantial differences in age-related incidence, natural history and response to treatment that exist according to cirrhosis aetiology, we predict that different approaches to surveillance may be justified according to different causes of cirrhosis.

\section{Limitations of the evaluation}

First, there is very little published evidence on which to base many of the parameter estimates for the model, and few data originate within the United Kingdom. This was particularly apparent for defining US performance. Second, as the primary focus of this evaluation was the effectiveness and cost-effectiveness of surveillance, we have used a simplified approach to modelling treatment in which OLT and resection are the only curative options available. We performed limited modelling of nonsurgical/ablative therapies as the evidence at the time of the analysis was inconclusive (Di Bisceglie, 2005). Recent evidence, predominantly from Asia (Izumi et al, 2007; Peng et al, 2007; Zytoon et al, 2007), suggests that such therapies may improve survival in patients with small tumours. If similarly promising findings could be shown in the United Kingdom, we would expect widespread adoption of such techniques to have beneficial cost-effectiveness implications, since a minimally invasive approach is much cheaper than OLT, and might also be expected to have less negative impact on quality of life. Third, we have assumed that entry to the surveillance programme is confined to those more likely to be considered eligible for the available curative treatment options (OLT or resection) and therefore assumes that high-risk activity (excessive alcohol consumption, intravenous drug use and so on) has ceased, and this may not be realistic. We have also assumed that the three cirrhosis aetiologies are mutually exclusive and acknowledge that many people develop cirrhosis as a result of multiple causes.

\section{Comparison with other studies}

There are no other studies published studies from Europe. We identified three comparable studies from our literature searches (Arguedas et al, 2003; Lin et al, 2004; Patel et al, 2005); all were conducted in the United States and simulated HCV-related cirrhosis only. In these studies, 6-monthly surveillance using AFP and US produced utility gains of between 0.23 and 0.49 QALYs, compared with no surveillance, giving ICERs of between $\$ 24500$ and $\$ 46600$ per QALY gained. Apart from obvious dissimilarities in input values and assumptions - reflecting the different populations and health-care systems simulated - there are substantial differences in the structures of the models. Crucially, ours is the only model to have accounted for tumour size in simulating the sensitivity of surveillance.

\section{Implications for future research}

Further research is required in the following areas (i) further modelling studies using alternative modelling methods such as individual patient sampling techniques could be used to account for heterogeneity in the patient population, so that factors such as tumour growth rate, tumour characteristics and the variability in individual patients' serial test results could be assessed. Such methods could also be used to assess the optimal surveillance 
strategy, the optimal surveillance interval and the effects of surveillance on waiting lists for OLT; (ii) further modelling studies could also investigate innovative surveillance strategies not currently undertaken in clinical practice (e.g., alternating AFP and US investigations at 6- or 12-monthly intervals, or measuring change in AFP levels following serial tests rather than absolute levels with fixed cutoff points); (iii) further empirical and modelling analysis of the impact of age at diagnosis of cirrhosis on the effectiveness and cost-effectiveness of surveillance; (iv) empirical evaluation of newer imaging techniques (e.g., contrastenhanced US) to detect HCCs; and (v) assessment of the effectiveness and cost-effectiveness of surveillance in other aetiologies (e.g., nonalcoholic fatty liver disease) and using other curative treatment options (e.g., ablative techniques).

\section{ACKNOWLEDGEMENTS}

This work is part of a larger project commissioned by the UK NHS R\&D HTA Programme (Project reference number 05/31/01). The views and opinions expressed herein are those of the authors and do not necessarily reflect those of the Department of Health. We gratefully acknowledge the help of the following: Christopher Chong and Murray Krahn for supplying raw EQ-5D data, which enabled us to calculate UK-specific utility estimates; Professor Howard Thomas and his team for providing cost data from the NHS HTA RCT and cost-effectiveness model of combination therapy for mild hepatitis C; UK Transplant for their assistance in providing liver-related data, in particular, Kerri Barber and Sue Pioli; Joanne Perry for invaluable administrative project support; Martin Pitt, Stuart Mealing, Ruth Garside and Rod Taylor for providing useful insights and the Expert Advisory Group for the project - Professor Graeme Alexander, Consultant Hepatologist, Cambridge Transplant Unit, Cambridge University Hospitals NHS Foundations Trust; Professor Andrew Burroughs, Consultant Hepatologist, Liver Transplant Unit, Royal Free Hospital (London); Mr Darius Mirza, Consultant Surgeon, the Liver Transplant and Hepatobiliary Unit, Queen Elizabeth Hospital (Birmingham); Dr John O'Grady, Consultant Hepatologist, Institute of Liver Studies, King's College Hospital (London); Professor William Rosenberg, Consultant Hepatologist, Wellcome Trust Clinical Research Facility, Southampton General Hospital; and Mr David Stell, Hepatobiliary Consultant, Derriford Hospital (Plymouth).

\section{REFERENCES}

Arguedas MR, Chen VK, Eloubeidi MA, Fallon MB (2003) Screening for hepatocellular carcinoma in patients with hepatitis $C$ cirrhosis: a costutility analysis. Am J Gastroenterol 98: 679-690

Baron RL, Brancatelli G (2004) Computed tomographic imaging of hepatocellular carcinoma. Gastroenterology 127(5 Suppl 1): S133-S143

Bennett GL, Krinsky GA, Abitbol RJ, Kim SY, Theise ND, Teperman LW (2002) Sonographic detection of hepatocellular carcinoma and dysplastic nodules in cirrhosis: correlation of pretransplantation sonography and liver explant pathology in 200 patients. AJR Am J Roentgenol 179: $75-80$

Brancatelli G, Baron RL, Peterson MS, Marsh W (2003) Helical CT screening for hepatocellular carcinoma in patients with cirrhosis: frequency and causes of false-positive interpretation. $A J R A m$ Roentgenol 180: $1007-1014$

Bruix J, Sherman M (2005) Management of hepatocellular carcinoma. Hepatology 42: $1208-1236$

Bruix J, Sherman M, Llovet JM, Beaugrand M, Lencioni R, Burroughs AK, Christensen E, Pagliaro L, Colombo M, Rodes J (2001) Clinical management of hepatocellular carcinoma. Conclusions of the Barcelona-2000 EASL conference. European Association for the Study of the Liver. J Hepatol 35: $421-430$

Chong CA, Gulamhussein A, Heathcote EJ, Lilly L, Sherman M, Naglie G, Krahn M (2003) Health-state utilities and quality of life in hepatitis C patients. Am J Gastroenterol 98: 630-638

Cottone M, Turri M, Caltagirone M, Maringhini A, Sciarrino E, Virdone R, Fusco G, Orlando A, Marino L, Pagliaro L (1988) Early detection of hepatocellular carcinoma associated with cirrhosis by ultrasound and alfafetoprotein: a prospective study. Hepatogastroenterology 35: $101-103$

Cottone M, Turri M, Caltagirone M, Parisi P, Orlando A, Fiorentino G, Virdone R, Fusco G, Grasso R, Simonetti RG, Pagliaro L (1994) Screening for hepatocellular carcinoma in patients with Child's A cirrhosis: an 8year prospective study by ultrasound and alphafetoprotein. J Hepatol 21: $1029-1034$

De Masi S, Tosti ME, Mele A (2005) Screening for hepatocellular carcinoma. Dig Liver Dis 37: $260-268$

Department of Health (DoH) (2005) Reference costs 2004. Department of Health: London. Available at http://www.dh.gov.uk/en/Publicationsandstatistics/ Publications/PublicationsPolicyAndGuidance/DH_4105545

Di Bisceglie AM (2005) Pretransplant treatments for hepatocellular carcinoma: do they improve outcomes? Liver Transpl 11: S10-S13

Ebara M, Ohto M, Shinagawa T, Sugiura N, Kimura K, Matsutani S, Morita M, Saisho H, Tsuchiya Y, Okuda K (1986) Natural history of minute hepatocellular carcinoma smaller than three centimeters complicating cirrhosis. A study in 22 patients. Gastroenterology 90: $289-298$
Farinati F, Marino D, De Giorgio M, Baldan A, Cantarini M, Cursaro C, Rapaccini G, Del Poggio P, Di Nolfo MA, Benvegnu L, Zoli M, Borzio F, Bernardi M, Trevisani F (2006) Diagnostic and prognostic role of alphafetoprotein in hepatocellular carcinoma: both or neither? $\mathrm{Am}$ Gastroenterol 101: 524-532

Fattovich G, Giustina G, Degos F, Tremolada F, Diodati G, Almasio P, Nevens F, Solinas A, Mura D, Brouwer JT, Thomas H, Njapoum C, Casarin C, Bonetti P, Fuschi P, Basho J, Tocco A, Bhalla A, Galassini R, Noventa F, Schalm SW, Realdi G (1997) Morbidity and mortality in compensated cirrhosis type C: a retrospective follow-up study of 384 patients. Gastroenterology 112: $463-472$

Fattovich G, Giustina G, Schalm SW, Hadziyannis S, Sanchez-Tapias J, Almasio P, Christensen E, Krogsgaard K, Degos F, Carneiro de MM (1995) Occurrence of hepatocellular carcinoma and decompensation in western European patients with cirrhosis type B. The EUROHEP Study Group on Hepatitis B Virus and Cirrhosis. Hepatology 21: $77-82$

Fattovich G, Pantalena M, Zagni I, Realdi G, Schalm SW, Christensen E, European Concerted Action on Viral Hepatitis (EUROHEP) (2002) Effect of hepatitis $\mathrm{B}$ and $\mathrm{C}$ virus infections on the natural history of compensated cirrhosis: a cohort study of 297 patients. Am J Gastroenterol 97: $2886-2895$

Fattovich G, Stroffolini T, Zagni I, Donato F (2004) Hepatocellular carcinoma in cirrhosis: incidence and risk factors. Gastroenterology 127: S35-S50

Fenwick E, Claxton K, Sculpher M (2001) Representing uncertainty: the role of cost-effectiveness acceptability curves. Health Econ 10: 779-787

Fenwick E, O'Brien B, Briggs A (2004) Cost-effectiveness acceptability curves - facts, fallacies and frequently asked questions. Health Econ 13: $405-415$

Government Actuary's Department (2006) Interim life tables (2002-2004) for England and Wales Available at http://www.gad.gov.uk/demography_ data/life tables/historical interim life tables.asp

Greten TF, Papendorf F, Bleck JS, Kirchhoff T, Wohlberedt T, Kubicka S, Klempnauer J, Galanski M, Manns MP (2005) Survival rate in patients with hepatocellular carcinoma: a retrospective analysis of 389 patients. Br J Cancer 92: $1862-1868$

HM Treasury (2003) Green Book: Appraisal and Evaluation in Central Government. TSO: London. Available at http://www.hm-treasury.gov.uk/ economic_data_and_tools/greenbook/data_greenbook_index.cfm

Izumi N, Asahina Y, Tsuchiya K, Kurosaki M, Nakanishi H, Kitamura T, Uchihara M, Miyake S (2007) Repeated radiofrequency ablation of the distant recurrence in the liver in patients with chronic hepatitis $\mathrm{C}$ virus infection achieving long-term survival. Hepatol Res 37(Suppl 2): S254-S263 
Kim CK, Lim JH, Lee WJ (2001) Detection of hepatocellular carcinomas and dysplastic nodules in cirrhotic liver: accuracy of ultrasonography in transplant patients. I Ultrasound Med 20: 99-104

Lai CWY, Wardle M, Birkett V, Powell E, Thomas GAO (2002) Surveillance for hepatocellular carcinoma in cirrhosis: a national audit of the practice in the UK. Gut 50: A114

Lin OS, Keeffe EB, Sanders GD, Owens DK (2004) Cost-effectiveness of screening for hepatocellular carcinoma in patients with cirrhosis due to chronic hepatitis C. Aliment Pharmacol Ther 19: 1159-1172

Liu WC, Lim JH, Park CK, Kim MJ, Kim SH, Lee SJ, Lee WJ, Lim HK (2003) Poor sensitivity of sonography in detection of hepatocellular carcinoma in advanced liver cirrhosis: accuracy of pretransplantation sonography in 118 patients. Eur Radiol 13: $1693-1698$

Llovet JM, Fuster J, Bruix J (1999) Intention-to-treat analysis of surgical treatment for early hepatocellular carcinoma: resection $v s$ transplantation. Hepatology 30: 1434-1440

Longworth L, Young T, Ratcliffe J, Bryan S, Buxton M (2001) Economic evaluation of the liver transplantation programme in England and Wales: an assessment of the costs of liver transplantation. Department of Health: London. Available at http://www.dh.gov.uk/en/Publicationsandstatistics/ Publications/PublicationsPolicyAndGuidance/DH 4005344

Oka H, Kurioka N, Kim K, Kanno T, Kuroki T, Mizoguchi Y, Kobayashi K (1990) Prospective study of early detection of hepatocellular carcinoma in patients with cirrhosis. Hepatology 12: 680-687

Patel D, Terrault NA, Yao FY, Bass NM, Ladabaum U (2005) Costeffectiveness of hepatocellular carcinoma surveillance in patients with hepatitis C virus-related cirrhosis. Clin Gastroenterol Hepatol 3: 75-84

Peng ZW, Zhang YJ, Chen MS, Liang HH, Li JQ, Zhang YQ, Lau WY (2008) Risk factors of survival after percutaneous radiofrequency ablation of hepatocellular carcinoma. Surg Oncol 17(1): 23-31 e-pub ahead of print

Ratcliffe J, Longworth L, Young T, Bryan S, Burroughs A, Buxton M (2002) Assessing health-related quality of life pre- and post-liver transplantation: a prospective multicenter study. Liver Transpl 8: 263-270

Roberts SE, Goldacre MJ, Yeates D (2005) Trends in mortality after hospital admission for liver cirrhosis in an English population from 1968 to 1999. Gut 54: $1615-1621$

Rode A, Bancel B, Douek P, Chevallier M, Vilgrain V, Picaud G, Henry L, Berger F, Bizollon T, Gaudin JL, Ducerf C (2001) Small nodule detection in cirrhotic livers: evaluation with US, spiral CT, and MRI and correlation with pathologic examination of explanted liver. J Comput Assist Tomogr 25: $327-336$

Ryder S (2003) Guidelines for the diagnosis and treatment of hepatocellular carcinoma (HCC) in adults. Gut 52: iii1 - iiis
Sherman M (2001) Alphafetoprotein: an obituary. J Hepatol 34: $603-605$

Sheu JC, Sung JL, Chen DS, Yang PM, Lai MY, Lee CS, Hsu HC, Chuang CN, Yang PC, Wang TH (1985) Growth rate of asymptomatic hepatocellular carcinoma and its clinical implications. Gastroenterology 89(2): $259-266$

Sonnenberg FA, Beck JR (1993) Markov models in medical decision making: a practical guide. Med Decis Making 13: $322-338$

Spreafico C, Marchiano A, Mazzaferro V, Frigerio LF, Regalia E, Lanocita R, Patelli G, Andreola S, Gaxbagnati F, Damascelli B (1997) Hepatocellular carcinoma in patients who undergo liver transplantation: sensitivity of CT with iodized oil. Radiology 203(2): 457-460

Taouli B, Goh JS, Lu Y, Qayyum A, Yeh BM, Merriman RB, Coakley FV (2005) Growth rate of hepatocellular carcinoma: evaluation with serial computed tomography or magnetic resonance imaging. J Comput Assist Tomogr 29: 425-429

Taouli B, Losada M, Holland A, Krinsky G (2004) Magnetic resonance imaging of hepatocellular carcinoma. Gastroenterology 127(Suppl 1): S144-S152

Trevisani F, De NS, Rapaccini G, Farinati F, Benvegnu L, Zoli M, Grazi GL, Del PP, Di N, Bernardi M, Italian Liver Cancer Group (2002) Semiannual and annual surveillance of cirrhotic patients for hepatocellular carcinoma: effects on cancer stage and patient survival (Italian experience). Am J Gastroenterol 97: 734-744

Trevisani F, D'Intino PE, Morselli-Labate AM, Mazzella G, Accogli E, Caraceni P, Domenicali M, De Notariis S, Roda E, Bernardi M (2001) Serum alpha-fetoprotein for diagnosis of hepatocellular carcinoma in patients with chronic liver disease: influence of $\mathrm{HBsAg}$ and anti-HCV status. J Hepatol 34: $570-575$

Valls C, Cos M, Figueras J, Andia E, Ramos E, Sanchez A, Serrano T, Torras J (2004) Pretransplantation diagnosis and staging of hepatocellular carcinoma in patients with cirrhosis: value of dual-phase helical CT. Am J Roentgenol 182(4): 1011-1017

Wright M, Grieve R, Roberts J, Main J, Thomas HC (2006) Health benefits of antiviral therapy for mild chronic hepatitis C: randomised controlled trial and economic evaluation. Health Technol Assess 10: 1-113, iii

Zoli M, Magalotti D, Bianchi G, Gueli C, Marchesini G, Pisi E (1996) Efficacy of a surveillance program for early detection of hepatocellular carcinoma. Cancer 78: 977 -985

Zytoon AA, Ishii H, Murakami K, El-Kholy MR, Furuse J, El-Dorry A, ElMalah A (2007) Recurrence-free survival after radiofrequency ablation of hepatocellular acrcinoma. A registry report of the impact of risk factors on outcome. Jpn J Clin Oncol 37: 658-672 